URL : https://ojs.unimal.ac.id/index.php/ekonomika/article/view/982

\title{
PENGARUH DANA SIMPAN PINJAM PEREMPUAN TERHADAP \\ PENINGKATAN PENDAPATAN USAHA MENJAHIT DI DESA LEUBU ME KECAMATAN MAKMUR KABUPATEN BIREUEN
}

\author{
Rahmaniar $^{\mathrm{a} 1}$, Cut Putri Mellita Sari ${ }^{\mathrm{a} 2}$ \\ ${ }^{a}$ Fakultas Ekonomi dan Bisnis Universitas Malikussaleh \\ 1Corresponding author : rahmaniarekp@gmail.com \\ 2 cmellita0674@gmail.com
}

\section{A R T I CLE I NFORMATION}

A B S T R A C T

\section{Keywords:}

Savings and Loans Funds and Operating Income.
This study aims to analyze the effect of women's savings and loan to increase sewing business income in Leubu Me Village, Makmur District, Bireun Regency. This study uses primary data from 45 respondents. The analytical method used is a simple linear regression method. The results of the research partially indicated that savings and loan $(\mathrm{X})$ significantly influence the increase in sewing business income (Y) in Leubu Me Village, Makmur District, Bireun Regency.

\section{1.}

\section{PENDAHULUAN}

Suatu kelompok atau individu masyarakat dikatakan sejahtera apabila sebagian besar kebutuhannya terpenuhi. Namun seringkali terjadi kesenjangan yang tinggi antara kebutuhan dengan kemamp uan manusia dalam memenuhinya. Besarnya tuntutan hidup yang dihadapi manusia saat ini terkadang tidak sesuai dengan kemampuan manusia itu sendiri, mengakibatkan manusia tidak berdaya yang akhirnya menjadi penyebab utama dari kemiskinan.Oleh karena itu, salah satu tolak ukur yang dapat digunakan untuk mengidentifikasi kesejahteraan dari masyarakat adalah melalui seberapa besar tingkat kemiskinan yang ada.Kemiskinan adalah fenomena yang bukan saja terjadi di Indonesia tetapi juga terjadi di sebagian besar negara -negara berkembang di dunia.

Bentuk-bentuk kegiatan dalam pelaksanaan Program Nasional Pemberdayaan Masyarakat Mandiri Perdesaan (PNPM-MP) di Desa Leubu Me Kecamatan Makmur Kabupaten Bireuen adalah program peningkatan kualitas hidup (PKH) melalui berbagai penyuluhan dan pelatihan, pembangunan fisik sarana dan prasarana, serta pemberian bantuan pinjaman modal usaha melalui Unit Ekonomi Produktif
(UEP) dan Simpan Pinjam Perempuan (SPP) yang penyaluran dana yang diberikan kepada kelompok masyarakat di desa. Seperti yang biasa terjadi dalam berbagai macam program pemberdayaan dan pengentasan kemiskinan, terdapat berbagai masalah yang terjadi dalam proses pelaksanaan program.

Berdasarkan observasi peneliti tentang SPP di Desa Leubu Me Kecamatan Makmur pada usaha menjahit sebagai berikut.

\section{Tabel. 1}

\section{Modal dan Pendapatan Usaha Menjahit di Desa Leubu Me Kecamatan Makmur Kabupaten Bireuen}

\begin{tabular}{|l|l|c|c|}
\hline No. & Usaha & Modal (Rp) & $\begin{array}{c}\text { Pendapatan } \\
(\mathrm{Rp})\end{array}$ \\
\hline 1. & Aminah & 4.019 .000 & 2.300 .000 \\
\hline 2. & Muzdalifah & 6.000 .000 & 1.500 .000 \\
\hline 3. & Afnidar & 5.000 .000 & 1.800 .000 \\
\hline 4. & Suherni & 8.500 .000 & 2.100 .000 \\
\hline 5. & Yulia & 4.400 .000 & 2.700 .000 \\
\hline
\end{tabular}

Sumber: Data Primer (2017)

Berdasarkan Tabel 1 tersebut disimpulkan dalam penelitian ini semakin besar modal maka pendapatan usaha semakin kecil.Dalam hal ini dikarenakan modal yang besar tidak mampu menunjang produksi yang lebih banyak yang dapat meningkatkan keuntungan usaha. Dari Tabel 1 diketahui bahwa usaha Yulia dengan modal yang 
kecil Rp. 4.400.000,- mampu memperoleh pendapatan yang besar yaitu Rp. 2.700.000,-. Sedangkan usaha Suherni dengan modal Rp. 8.500.000,- hanya memperoleh pendapatan Rp. 2.100.000,-.

Adapun tujuan dalam penelitian ini adalah untuk mengetahui pengaruhdana simpan pinjam perempuan berpengaruh terhadap peningkatan pendapatan Usaha Menjahit di Desa Leubu Me Kecamatan Makmur Kabupaten Bireuen.

Bagian kedua dari penelitian ini akan membahas tinjauan teoritis, metode penelitian akan dibahas pada bagian ketiga. Kemudian pada bagian ke empat akan dibahas hasil penelitian dan pembahasan. Pada bagian kelima akan membahas kesimpulan dan saran.

\section{TINJAUAN TEORITIS}

\section{Pengertian Dana Simpan Pinjam Perempuan}

SPP merupakan penyaluran dana pinjaman bergulir bagi kelompok perempuan dalam skala mikro (mikro finance). Dana yang dialokasikan untuk kegiatan SPP yaitu 25 persen dari total dana Bantuan Langsung Tunai (BLM) per kecamatan. Dalam penelitian ini yang dimaksud pemberdayaan adalah pemberdayaan yang dilakukan terhadap perempuan.

\section{Azas-Azas Pembiayaan}

Menurut (Antonio, 2011) azas-azas pembiayaan terdiri dari 4 aspek yaitu sebagai berikut:

\section{Asas Kepercayaan}

Dalam asas transaksi pembiayaan modal kerja seperti halnya dengan pinjamankredit pada bank konvensional adalah didasarkan kepada asas kepercayaan. Dengandemekian asas transaksi pembiayaan ini hanya bisa bila ada kesepakatan dan salingpercaya natara debitur dan kreditur.Oleh karena itu, bagi calon nasabah yang ingin memperoleh modal dari bankmaka dia harus terlebih dahulu mengajukan surat permohonan kepadapihak bank,yang mana dalam surat permohonan tersebut juga harus dicantumkan modal yang diperlikan debitur.

\section{Asas Selektifitas dan Hati-Hati}

Sebagai kelanjutan dari asas diatas, sebelum memberikan modal kepadamudharib atau mitra usaha, bank akanmelakukan analisis atas penilaian yang sangatselektif dan hati-hati terhadap setiap permohonan modal yang telah diajukan debiturselaku mitra usaha. Untuk melakukan penilaian itu, maka setiap personil bankdituntut kemampuannya yang sangat handal dan jeli dalam menangani hal tersebut.

Untuk melakukan analisis terhadap calon debitur selaku mitra usaha, makapihak bank perlu menurunkan petugas bank yang handal ke dalam permasalahancalon debitur/mitra usaha untuk memeriksa keadaan keuangannya, kegiatan usahayang akan dijalankan maupun dari segi lainnya untuk menilai apakah perusahaandebitur telah memenuhi prinsip-prinsip atau syarat-syarat yang telah ditetapkanoleh pihak bank.

\section{Asas saling menguntungkan}

Disamping asas-asas diatas yang telah ditetapkan oleh bank Islam ataspembiayaan yang akan diberikan kepada nasabah, adalah harus berakhir sama-samamengutungkan, mempunyai kesamaan dalam kesepakatan, saling mempercayai, danharuslah jelas usaha yang akan dijalankan oleh si usahawan.

Agar asastersebut dapat tercapai maka dalam prinsip pembiayaan modal kerjapada bank syariah, juga dilakukan pengawasan terhadap kegiatan si mudharib selakumitra usaha.Program pengawasan ini dilakukan berdasarkan pedoman dan ketentuanyang digariskan oleh Bank Indonesia (BI) dan Syariah Islam dengan fokus padapemeriksaan kuantitas dan kualitas dari setiap jenis transaksi.

\section{Asas Husnuzzandan Pengawasan}

Asas lain yaitu Asas Husnuzzan (berpransangka baik) dan pengawasan sedinimungkin. Adapun tujuan dan sasarandari pengawasan ini selama terjalin hubunganbaik antara kedua belah pihak adalah agar setiap kegiatan operasional bank syariahIndonesia berada di jalur yang sesuai dengan konsep syariat islam serta ketentuanperbankan lainnya dan sesuai dengan prinsip manajemen propesional serta 
pedomanyang digariskan dewan komisaris, Dewan pengawas syariah dan Direksi. Sehinggasemua tujuan yang digariskan tersebut dicapai dengan cara efisien, efektif dan cepat.

\section{Modal Kerja}

Modal kerja adalah pembiayaan yang ditujukan untuk memenuhi sesuatu kebutuhan dari pengusaha dalam suatu bidang usaha (Purwodarminto, 2007).

(Mardiyatmo, 2008) menyatakan bahwa Sumber dana darimodal asing dapat diperoleh dari:

a. Pinjaman dari dunia perbankan, baik dari perbankan swastamaupun pemerintah atau perbankan asing;

b. Pinjaman dari lembaga keuangan seperti perusahaanpegadaian, modal ventura, asuransi leasing, dana pensiun,koperasi atau lembaga pembiayaan lainnya;

c. Pinjaman dari perusahaan non keuangan.

\section{Pendapatan}

Menurut (Soediyono, 1992)"pendapatan adalah jumlah penghasilan yang diterima para anggota masyarakat untuk jangka waktu tertentu sebagai ba las jasa atas faktor -faktor produksi yang mereka sumbangkan dan turut serta mwmbwntuk produk nasional".

\section{Kerangka Konseptual}

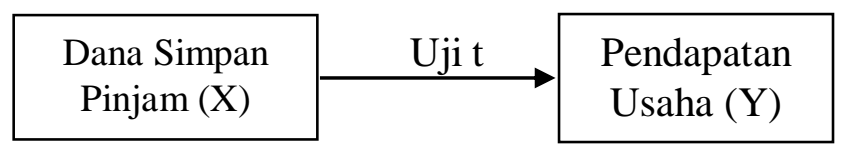

Gambar 1

\section{Kerangka Konseptual}

Berdasarkan gambar 1 kerangka konseptual di atas dapat dijelaskan bahwa dana simpan pinjam dapat meningkatkan pendapatan usaha. Dalam hal ini dana simpan pinjam yang tinggi mampu meningkatkan pendapatan usaha.

\section{Hipotesis Penelitian}

Berdasarkan rumusan masalah yang telah ditulis di bab sebelumnya, maka hipotesis dalam penelitian ini adalah:

Ho; Diduga tidak terdapat pengaruh dana simpan pinjam perempuan terhadap pendapatan usaha menjahit di Desa Leubu Me Kecamatan Makmur Kabupaten Bireuen.

Ha; Diduga terdapat pengaruh dana simpan pinjam perempuan terhadap pendapatan usaha menjahit di Desa Leubu Me Kecamatan Makmur Kabupaten Bireuen

\section{METODELOGI PENELITIAN}

\section{Populasi}

Populasi adalah seluruh unit yang akan dijadikan sasaran penelitian. Populasi dalam penelitian ini adalahkelompok Simpan Pinjam Perempuan SPP program PNPM Mandiri Perdesaandi Desa Leubu Me Kecamatan Makmur Kabupaten Bireuen yang berjumlah 5 kelompok usaha menjahit (Observasi awal).

\section{Sampel}

Peneliti mengambil teknik pengambilan sampel dengan metode sensus yaitu $100 \%$ dari populasi (total populasi) dijadikan sebagai sampel, sehingga jumlah sampel yang diambil adalah 5 kelompok yang terdiri dari 45 orang anggota.

\section{Teknik Pengumpulan Data}

Penulis mengumpulkan data yang diperlukan dengan cara menyebarkan kuisioner langsung pada masyarakat yang bersangkutan dan juga dokumentasi

\section{Operasional Variabel}

1. Dana simpan pinjam (variabel $\mathrm{X}$ )

Dana yang dikucurkan oleh PNPM kepada ketua kelompok gampong untuk dibagikan kepada anggota dengan satuan Rupiah (Rp).

2. Pendapatan usaha menjahit (Variabel Y)

Keseluruhan penghasilan atau penerimaan yang diperoleh para pemilik faktor produksi dalam suatu masyarakat selama 1 bulan dengan satuan Rupiah (Rp).

\section{Metode Analisis Data}

Untuk mempermudah analisis digunakan aplikasi pengolah data dengan program SPSS versi 20. Untuk mengetahui pengaruh variabel bebas 
terhadap variabel terikatnya digunakan rumus analisis regresi linier sebagai berikut:

$$
\mathrm{Y}=\mathrm{a}+\mathrm{bX}+\mathrm{e}
$$

dimana :

$\mathrm{Y}=$ dependent variabel (pendapatan usaha)

$\mathrm{a}=$ konstanta

$\mathrm{b}_{1}=$ koefisien regresi (dana simpan pinjam)

$\mathrm{X}=$ independent variabel (dana simpan pinjam)

$\mathrm{e}=$ error

\section{HASIL PENELITIAN DAN PEMBAHASAN}

\section{Karakteristik Responden}

Adapun deskripsi data karakteristik responden dalam penelitian yang mencakup jenis kelamin responden, usia responden, pendidikan responden, jumlah pekerja, dan pendapatan usaha responden, maka diperoleh data sebagai berikut :

Tabel 2

Karakteristik Responden Berdasarkan Jenis Kelamin

\begin{tabular}{|l|c|c|c|c|}
\hline & Frequency & Percent & Valid Percent & $\begin{array}{c}\text { Cumulative } \\
\text { Percent }\end{array}$ \\
\hline Valid Perempuan & 45 & 100.0 & 100.0 & 100.0 \\
\hline
\end{tabular}

Sumber: Hasil Penelitian, 2018

Berdasarkan tabel 2, diketahui bahwa total mayoritas yang menjadi responden dalam penelitian ini semua perempuan yang berjumlah 45 atau $100 \%$. Hal ini dikarenakan tidak ada pria yang bekerja pada bidang usaha menjahit.

Berikut ini adalah karateristik responden berdasarkan usia. Diperoleh data sebagai berikut:

\section{Tabel 3}

\section{Karakteristik Responden Berdasarkan Usia}

\begin{tabular}{|c|c|c|c|c|}
\hline & Frequency & Percent & Valid Percent & $\begin{array}{c}\text { Cumulative } \\
\text { Percent }\end{array}$ \\
\hline Valid 23-26 tahun & 5 & 11.1 & 11.1 & 11.1 \\
27-30 tahun & 4 & 8.9 & 8.9 & 20.0 \\
31-34 tahun & 12 & 26.7 & 26.7 & 46.7 \\
35-38 tahun & 9 & 20.0 & 20.0 & 66.7 \\
39-42 tahun & 6 & 13.3 & 13.3 & 80.0 \\
43-46 tahun & 8 & 17.8 & 17.8 & 97.8 \\
47-50 tahun & 1 & 2.2 & 2.2 & 100.0 \\
Total & 45 & 100.0 & 100.0 & \\
\hline
\end{tabular}

Sumber: Hasil Penelitian, 2018
Berdasarkan tabel 3 di atas, dapat diketahui bahwa mayoritas responden usia 31 - 34 tahun.

Berikut ini adalah karakteristik responden berdasarkan pendidikan terakhir. Diperoleh data sebagai berikut:

\section{Tabel 4}

Karakteristik Responden Berdasarkan Pendidikan Terakhir

\begin{tabular}{|cc|c|c|c|c|}
\hline & Frequency & Percent & Valid Percent & $\begin{array}{c}\text { Cumulative } \\
\text { Percent }\end{array}$ \\
\hline Valid & SMA & 39 & 86.7 & 86.7 & 86.7 \\
& S1 & 6 & 13.3 & 13.3 & 100.0 \\
& Total & 45 & 100.0 & 100.0 & \\
\hline
\end{tabular}

Sumber: Hasil Penelitian, 2018

Berdasarkan dari tabel 4 dapat diperoleh data karakteristik responden berdasarkan pendidikan terakhir, sebagian besar dari responden yang berjumlah $39(86,7 \%)$ orang adalah berpendidikan tamatan SMA atau sederajat dan 6 $(13,3 \%)$ orang responden berpendidikan tamatan perguruan tinggi.

\section{Analisis Deskriptif}

Variabel bebas dalam penelitian ini terdiri dari 2 variabel yakni Dana Simpan Pinjam (X) dan Pendapatan Usaha (Y). Berikut disajikan kecenderungan jawaban pemilik usaha menjahit pada setiap indikatornya masing-masing.

\section{Dana Simpan Pinjam}

\section{Tabel 5}

Dana Simpan Pinjam

\begin{tabular}{|lc|c|c|c|c|}
\hline & & Frequency & Percent & Valid Percent & $\begin{array}{c}\text { Cumulative } \\
\text { Percent }\end{array}$ \\
\hline Valid & $4.2-4.7$ juta & 9 & 20.0 & 20.0 & 20.0 \\
& $5.4-5.9$ juta & 18 & 40.0 & 40.0 & 60.0 \\
& $6.0-6.5$ juta & 9 & 20.0 & 20.0 & 80.0 \\
$7.8-8.3$ juta & 9 & 20.0 & 20.0 & 100.0 \\
Total & 45 & 100.0 & 100.0 & \\
\hline
\end{tabular}

Sumber: Hasil Penelitian, 2018

Berdasarkan dana simpan pinjam, mayoritas pengusaha menjahit memiliki pinjaman Rp. 5,4-5,9 juta perorang. 
2. NilaiPendapatan Usaha

Tabel 6

Pendapatan

\begin{tabular}{|l|c|c|c|c|}
\hline & Frequency & Percent & Valid Percent & $\begin{array}{c}\text { Cumulative } \\
\text { Percent }\end{array}$ \\
\hline Valid 1.5 -1.6 juta & 1 & 2.2 & 2.2 & 2.2 \\
1.7-1.8 juta & 6 & 13.3 & 13.3 & 15.6 \\
1.9-2.0 juta & 13 & 28.9 & 28.9 & 44.4 \\
2.1-2.2 juta & 8 & 17.8 & 17.8 & 62.2 \\
2.3-2.4 juta & 7 & 15.6 & 15.6 & 77.8 \\
2.5-2.6 juta & 7 & 15.6 & 15.6 & 93.3 \\
2.7-2.8 juta & 3 & 6.7 & 6.7 & 100.0 \\
Total & 45 & 100.0 & 100.0 & \\
\hline
\end{tabular}

Sumber: Hasil Penelitian, 2018

Berdasarkan pendapatan, mayoritas pengusaha menjahit memperoleh pendapatan sebesar Rp. 1,9-2,0 juta perbulan.

\section{Analisis Regresi Linear Sederhana}

Analisis linear sederhana bertujuan untuk mengetahui tingkat signifikan dan nilai koefisien dari variabel bebas terhadap variabel terikat. Selain itu analisis ini digunakan untuk mengetahui arah hubungan antara variabel independen dengan variabel dependen apakah masing-masing independen berhubungan positif atau negatif dan untuk memprediksi nilai dan variabel dependen apabila nilai variabel independen mengalami kenaikan atau penurunan. Dengan melakukan pengolahan data subtruktur dari analisis liner berganda, koefisien persamaan regrasi yang terdapat pada variabel dana simpan pinjam (X) dapat dipakai untuk memprediksikan hubungan dan sumbangan pada variabel pendapatan usaha (Y). Hasil analisis tersebut dapat dilihat pada tabel 7 berikut.

Tabel 7

Hasil Analisis Regresi Linear

\begin{tabular}{|c|c|c|c|c|c|}
\hline \multirow[b]{2}{*}{ Model } & \multicolumn{2}{|c|}{$\begin{array}{l}\text { Unstandardized } \\
\text { Coefficients }\end{array}$} & \multirow{2}{*}{\begin{tabular}{|c|}
$\begin{array}{c}\text { Standardized } \\
\text { Coefficients }\end{array}$ \\
Beta \\
\end{tabular}} & \multirow[b]{2}{*}{$\mathrm{T}$} & \multirow[b]{2}{*}{ Sig. } \\
\hline & B & $\begin{array}{l}\text { Std. } \\
\text { Error }\end{array}$ & & & \\
\hline $1 \quad$ (Constant) & 1683.028 & 220.336 & & 7.638 & .000 \\
\hline Dana_Simpan_Pinjam & .080 & .036 & .319 & 2.209 & .033 \\
\hline
\end{tabular}

a. Dependent Variable: Pendapatan_usaha

Berdasarkan hasil regresi linier yang di peroleh pada tabel 4.6 maka ditulis persamaan regresi linier yaitu :

$$
\mathbf{Y}=\mathbf{a}+\mathbf{b} \mathbf{X}+\mathbf{e}
$$

Dimana :

$$
Y=1688,028+0,080 X
$$

$\mathrm{a}=1688,028$ berarti bahwa nilai konstanta, ketika dana simpan pinjam perempuan konstan (bernilai 0), maka pendapatan yang diperoleh sebesar Rp. 1688,028.

$\mathrm{b}=$ koefisien regresi dana simpan pinjam sebesar 0,080 menyatakan bahwa apabila dana simpan pinjam meningkat sebesar Rp.1.000.000, maka pendapatan usaha akan meningkat sebesar Rp. 800.000.

Hasil analisis regresi berganda pada tabel 4.6 menunjukkan dana simpan pinjam perempuan memiliki pengaruh positif terhadap pendapatan usaha.

\section{Uji Asumsi Klasik \\ Uji Normalitas}

Ujinormalitas dilakukan dengan analisis grafik normal Probability Plot (pp plot).

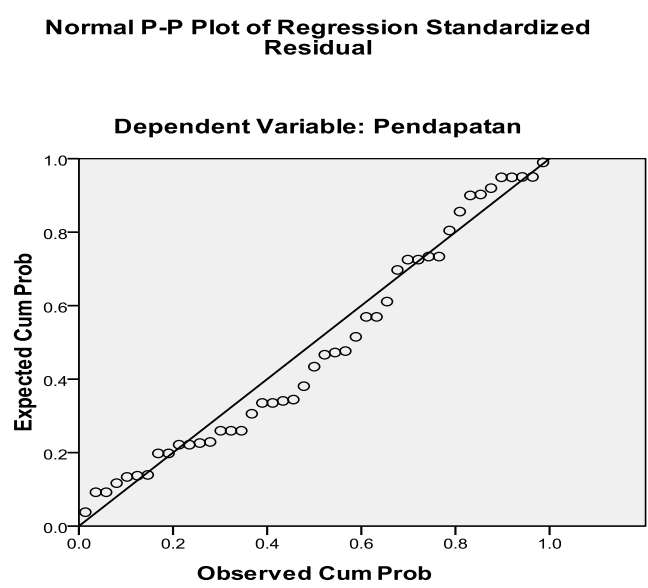

Dapat dilihat bahwa data menyebar disekitar garis diagonal dan mengikuti arah garis diagonal. Maka dapat disimpulkan bahwa variabel penelitian berdistribusi normal.

\section{Uji Heteroskedastisitas}

Model regresi yang baik adalah tidak terjadi heteroskedastisitas. Cara untuk mengetahui ada tidaknya heteroskedastisitas yaitu dengan melihat grafik Scatterplot variabel terikat (ZPERD) dengan residual (SRESID). 


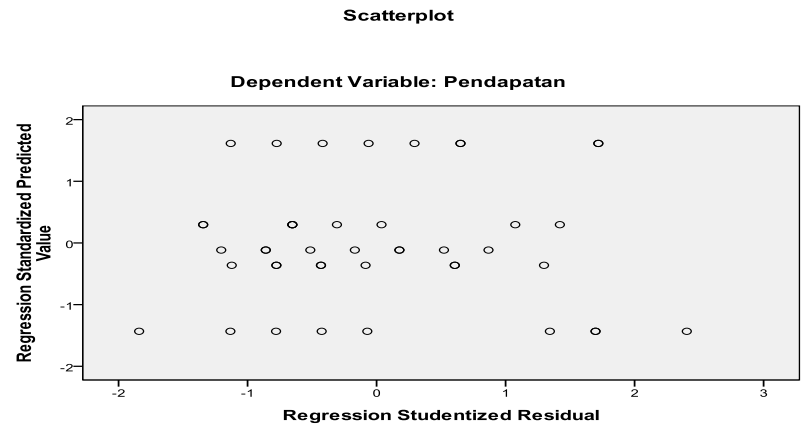

Pada gambar di atas dapat dijelaskan bahwa semua data penelitian menyebar di atas dan di bawah angka nol pada sumbu Y dan titiktitik menyebar tanpa membentuk pola. Yang berarti penelitian ini tidak terjadi heteroskedastisitas.

\section{Pengujian Hipotesis}

\section{Uji Koefisien Determinasi $\left(\mathbf{R}^{\mathbf{2}}\right)$}

Nilai koefisien determinasi untuk variabel bebas lebih dari dua digunakan Adjusted R Square. Hasil dari koefisien determinasi dapat dilihat pada tabel 4.7 sebagai berikut;

\section{Tabel 8}

\section{Koefisien Determinasi}

\begin{tabular}{|c|c|c|c|c|}
\hline Model & $\mathrm{R}$ & R Square & $\begin{array}{c}\text { Adjusted R } \\
\text { Square }\end{array}$ & $\begin{array}{c}\text { Std. Error of the } \\
\text { Estimate }\end{array}$ \\
\hline 1 & $.319^{\mathrm{a}}$ & .102 & .081 & 292.920 \\
\hline
\end{tabular}

Berdasarkan tabel 8 di atas dari hasil koefisien determinasi dapat diketahui bahwa nilai $\mathrm{R}^{2}=0,102$, ini berarti bahwa hubungan antara variabel dana simpan pinjam adalah sebesar $10,2 \%$ sedangkan sisanya sebesar $89,8 \%$ dipengaruhi oleh variabel lain diluar penelitian ini berupa variabel volume produksi dan tenaga kerja.

\section{Koefisien Korelasi (R)}

Berdasarkan tabel di atas dari hasil koefisien korelasi dapat diketahui bahwa nilai $\mathrm{R}$ $=0,319(31,9 \%)$ ini berarti bahwa dana simpan pinjam mempunyai hubungan yang lemah dan positif terhadap pendapatan usaha menjahit di Desa Leubu Me Kecamatan Makmur Kabupaten Bireuen.
Uji t

\begin{tabular}{|c|c|c|c|c|c|}
\hline \multirow[b]{2}{*}{ Model } & \multicolumn{2}{|c|}{$\begin{array}{l}\text { Unstandardized } \\
\text { Coefficients }\end{array}$} & \multirow{2}{*}{\begin{tabular}{|c|}
$\begin{array}{c}\text { Standardized } \\
\text { Coefficients }\end{array}$ \\
Beta \\
\end{tabular}} & \multirow[b]{2}{*}{$\mathrm{T}$} & \multirow[b]{2}{*}{ Sig. } \\
\hline & B & $\begin{array}{l}\text { Std. } \\
\text { Error }\end{array}$ & & & \\
\hline $1 \quad$ (Constant) & 1683.028 & 220.336 & & 7.638 & .000 \\
\hline Dana_Simpan_Pinjam & 080 & .036 & .319 & 2.209 & .033 \\
\hline
\end{tabular}

Pengolahan data uji statistik t-test (Parsial) menunjukan:

Dana simpan pinjam memiliki nilai signifikansi (Sig.) 0,033 dengan nilai $\alpha \quad 0,05$. Sedangkan nilai t hitung nilai dana simpan pinjam sebesar 2,209 dengan derajat sig 0,05 artinya t tabel berada pada nilai 2,016. artinya $t$ hitung $(2,209)>$ dari $\mathrm{t}$ tabel (2,016), maka $\mathrm{H}_{\mathrm{a}}$ diterima (ada pengaruh dana simpan pinjam terhadap pendapatan usaha).

\section{KESIMPULAN DAN SARAN Kesimpulan}

Hasil analisis data dan pembahasan terhadap tujuan penelitian tentang pengaruh danan simpan pinjam perempuan terhadap peningkatan pendapatan usaha menjahit di Desa Leubu Me Kecamatan Makmur Kabupaten Bireuen dapat disimpulkan bahwa variabel dana simpan pinjam berpengaruh dan signifikan terhadap pendapatan usaha.

\section{Saran}

Berdasarkan penelitian mengenai pendapatan usaha menjahit di Desa Leubu Me Kecamatan Makmur Kabupaten Bireuen, maka dapat disampaikan saran yaitu:

1. Pemerintah daerah, diharapkan untuk lebih meningkatkan pelatihan-pelatihan atau pemberian modal usaha guna menambah wawasan para pekerja dan pemilik usaha menjahit agar menambah pengalaman serta meningkatkan usaha menjahit.

2. Mencari alternatif perolehan bahan baku dari tempat lain yang memiliki harga lebih murah sehingga dapat menekan biaya dan menambah daya saing dengan usaha menjahit daerah lain. 


\section{DAFTAR PUSTAKA}

Antonio. (2011). Bank Syariah Dari Teori Ke

Praktik. Depok: Gema insani.

Mardiyatmo. (2008). Kewirausahaan. Jakarta:

Penerbit Yudisthira.

Purwodarminto. (2007). Kamus Umum Bahasa

Indonesia. Jakarta: PN Balai Pustaka.

Soediyono. (1992). Ekonomi Makro. Yogyakarta:

Liberty.

Faisal, Sanapiah. (1999). Metode Penelitian

Kuantitatif. Jakarta: Raja Grafindo Persada.

Mankiw, N. Gregory. 2006. Makro Ekonomi

Edisi Keenam. Erlangga. Jakarta

Manurung, Mandala. 2008. Teori Ekonomi

Makro. Edisi. Keempat : PT Gramedia

Pustaka Utama. Jakarta.

Sugiarto, \& Dkk. (2007). Ekonomi Mikro:

Sebuah Kajian Komprehensif. PT.

Gramedia Pustaka Utama: Jakarta.

Sukirno, S. (2004). Makroekonomi Edisi

Ketiga. PT Raja Grafindo Persada: Jakarta. 